\title{
Violência nas primeiras letras: a escola num conto de Machado de Assis
}

\author{
Sílvia Craveiro Gusmão Garcia ${ }^{1}$ \\ Antonio Manoel dos Santos Silva ${ }^{2}$
}

GARCIA, S. C. G., SILVA, A. M. S. Violence in early education: school as depicted in a short story by Machado de Assis, Interface _ Comunicação, Saúde, Educação, v.3 , n.5, 1999.

Based on Conto de Escola (School Tale), by Machado de Assis, this text provides a reflection on the issue of violence in the history of our education, analyzing the process of schooling that was in force in Brazil up to the nineteenth century. This consisted of the teacher dominating pupils by means of instruments of fear and coercion, with the purpose of building their character, even though, to this end, teachers resorted to acts of violence. With this analysis as a starting point, it became apparent that the greater the extent to which power depends on maintaining the privileges of a given class, the greater the extent to which violence will prevail in the social structure and, therefore, in education, as one of its institutions.

KEY WORDS: character building; education; violence.

Baseando-se no Conto de Escola, de Machado de Assis, o texto reflete sobre a questão da violência na nossa história da educação, analisando o processo de formação escolar, vigente no Brasil até o século XIX, que consistia em o professor sujeitar seus alunos por meio de instrumentos de coerção e medo, com o fim de formar-lhes o caráter, mesmo que para isso recorresse a atos violentos. A partir das análises desenvolvidas, pode-se pensar que quanto mais o poder se fundar na manutenção de privilégios de uma classe, mais a violência se impõe na estrutura social e, portanto, na educação, como uma de suas instituições.

PALAVRAS-CHAVE: formação do caráter; educação; violência.

\footnotetext{
${ }^{1}$ Pós-graduanda em Literatura Brasileira, Instituto de Biociências, Letras e Ciências Exatas, IBILCE-UNESP, São José do Rio Preto, SP.

${ }^{2}$ Professor do Departamento de Letras Vernáculas do IBILCE-UNESP, São José do Rio Preto, SP.
} 
Machado de Assis (1839-1908) publicou em 1884 o conto Conto de Escola, recolhido em 1896 no livro Várias Histórias. Além de fazer parte de um livro que se considera como o apogeu da narrativa curta machadiana, o conto possui também valor estilístico próprio e características distintivas, já assinaladas pela crítica: apóia-se, muito provavelmente, em reminiscências da infância, harmoniza a narrativa de personagem com a narrativa analítica e concentra seu foco crítico e reflexivo sobre a formação do caráter. Tratase de um conto sobre educação e sobre a escola.

O conto está narrado em primeira pessoa, abrindo-se com uma precisa indicação de data e de local:

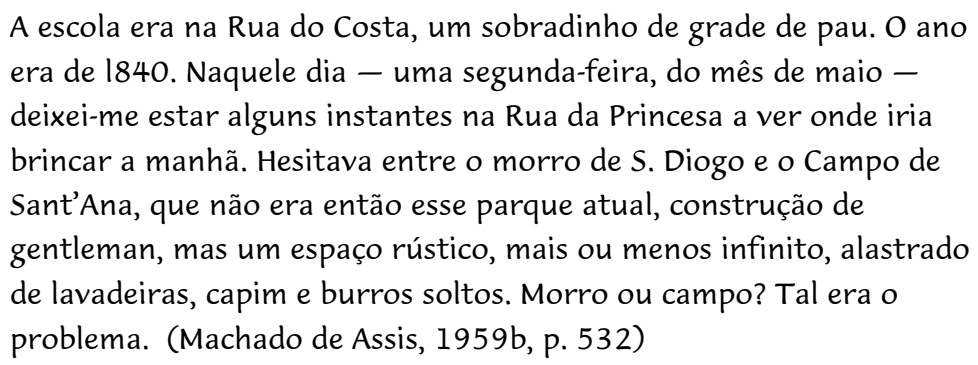

O menino Pilar (o narrador quando criança), hesitante entre os espaços livres e abertos, locais para brincar, acaba optando pela escola. Motivo da opção: o castigo que o pai lhe aplicara (uma sova de vara de marmeleiro), por ter faltado duas vezes às aulas. Já na escola, recebe de outro menino, Raimundo, filho do mestre, uma proposta: trocar uma explicação por uma moeda de prata. Outro aluno, Curvelo, vai ao mestre e delata os colegas. $\mathrm{O}$ severo professor, Policarpo, castiga os meninos, batendo neles com a palmatória. Pilar promete vingar-se, mas Curvelo foge com medo. No dia seguinte, após sonhar com a moeda, Pilar sai com a intenção de procurá-la, já que o mestre, antes da punição, a havia atirado à rua. Estando a procurar a moeda, Pilar se sente atraído por um batalhão de fuzileiros. Acompanha-o $e$ depois retorna para casa sem moeda e sem ressentimentos. Adulto, o narrador, rememorando esses fatos, salienta que Raimundo e Curvelo foram os primeiros a lhe mostrar a existência da corrupção e da delação.

$\mathrm{O}$ conto nos mostra de imediato o problema da relação entre professor $e$ alunos, bem como o problema da formação moral. Sobre o primeiro, lembre-se Gilberto Freyre que vamos citar e comentar, antes de voltarmos ao objeto de nossa análise:

E felizes dos meninos que aprenderam a ler e a escrever com professores negros, doces e bons. Devem ter sofrido menos que os outros: os alunos de padres, frades, "professores pecuniários", mestresrégios - estes uns ranzinzas terríveis, sempre fungando rapé; velhos caturras de sapato de fivela e vara de marmelo na mão. Vara ou palmatória. Foi à força de vara e palmatória que os “antigos”, nossos avós e bisavós, aprenderam Latim e Gramática; Doutrina e História Sagrada. (1987, p. 417) 
Ao descrever o martírio do ensino colonial antes da Independência - e mesmo que se desconte a idealização morenizadora - Gilberto Freyre está, na verdade, chamando a atenção para os regulamentos rígidos do sistema escolar desde o seu nascimento. A escola brasileira, desde a origem, absorveu o mesmo conceito de educação que vigorava nas famílias: disciplina rígida com severas punições. A disciplina se entendia como um instrumento de controle do professor sobre os alunos, um instrumento tanto mais eficaz quanto mais pesada fosse a mão que com ele operasse o corpo transido pelo medo.

Não é demais lembrar que a pedagogia, como disciplina patriarcal, apoiou-se em grande parte nas condições de coerção com que se formou o Brasil: de conquistadores sobre conquistados e de senhores sobre escravos. Gilberto Freyre assim ilustrou esse quadro:

\begin{abstract}
Nos antigos colégios, se houve por um lado, em alguns casos, lassidão - fazendo-se vista grossa a excessos, turbulências e perversidades dos meninos - por outro lado abusou-se criminosamente da fraqueza infantil. Houve verdadeira volúpia em humilhar a criança; em dar bolo em menino. Reflexo da tendência geral para o sadismo criado no Brasil pela escravidão e pelo abuso do negro. O mestre era um senhor todo-poderoso. Do alto de sua cadeira, que depois da Independência tornou-se uma cadeira quase de rei, com a coroa imperial esculpida em relevo no espaldar, distribuía castigos com o ar terrível de um senhor de engenho castigando negros fujões. Ao vadio punha de braços abertos; ao que fosse surpreendido dando uma risada alta, humilhava com um chapéu de palhaço na cabeça para servir de mangação à escola inteira; a um terceiro, botava de joelhos sobre grãos de milho. Isso sem falarmos da palmatória e da vara - esta, muitas vezes com um espinho ou um alfinete na ponta, permitindo ao professor furar de longe a barriga da perna do aluno. (1987, p. 419)
\end{abstract}

O menino no Brasil foi vítima, quase tanto quanto o escravo, do sadismo patriarcal. Esteve sujeito a diversas formas (moral, sentimental, física) $e$ instrumentos de sofrimento: as várias espécies de palmatória, a vara de marmelo, às vezes com alfinete na ponta, o galho de goiabeira, o cipó, a pancada ou o empurrão no cachaço, o puxavante de orelha, o beliscão simples, o beliscão de frade, o cascudo, a palmada, o safanão. A lista
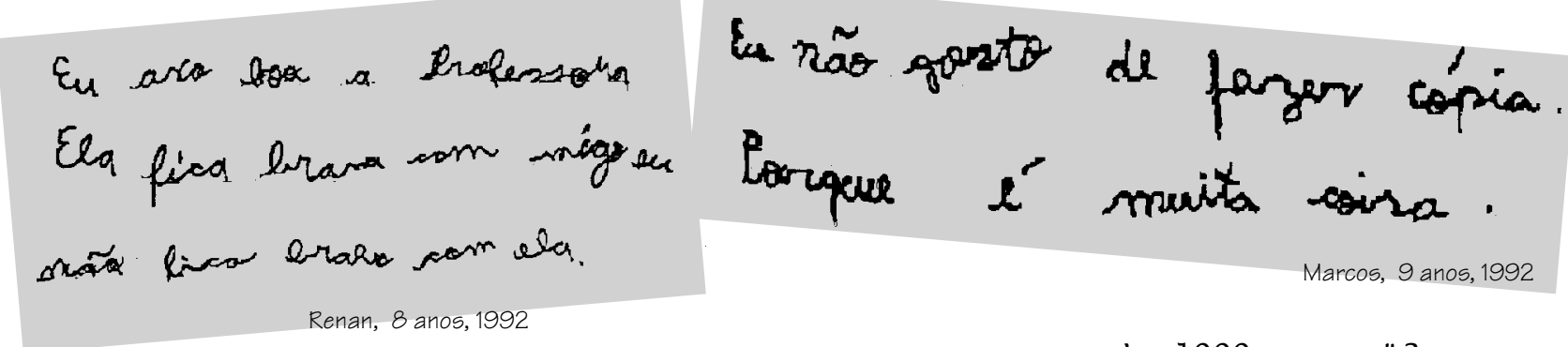

agosto, 1999 
poderia aumentar se acrescentássemos os castigos descritos pelo padre Jerônimo Serpa no Tratado de Educação Física-Moral dos Meninos, publicado no começo do século XIX. Esse padre, que condena os castigos, fala do raspar a cabeça à navalha, do açoite, das horas em joelhos sobre caroço de milho etc., como exemplos dos maus tratos comuns nas casas e nas escolas.

Lembremos que, nos dois primeiros séculos de Brasil colonial, os colégios dos jesuítas, depois os seminários e colégios de padres, foram os grandes responsáveis pela irradiação de cultura. Nesse sistema educacional, a ordem e a autoridade primavam sobre tudo; os castigos, inclusive corporais, dados por irmãos leigos e não pelos padres, faziam parte do processo educativo. $\mathrm{O}$ castigo do "pensum", por exemplo, que consistia em copiar dezenas ou centenas de vezes a mesma frase, a mesma página ou até livro inteiro, foi substituído pelo castigo corporal.

Em 1827, na reunião da Comissão de Instrução Pública da Câmara dos Deputados, foi apresentada a emenda de Baptista Pereira e Cunha Mattos, buscando terminar com as punições: "Ficam proibidos os castigos corporais, sob pena de culpa” (Moacyr, 1936, p. 187). A réplica, no entanto, veio logo em seguida, quando o Sr. Hollanda Cavalcanti disse presumir que muito pouca gente soubesse realmente ensinar sem o uso da palmatória, completando que "quanto não dizem hoje: 'ah! se meu mestre me desse bastante pancada eu seria hoje mais feliz'. Para que excluir a palmatória?" (Moacyr, 1936, p. 187). Pouco mais de cem anos depois, lê-se numa crônica de Mário de Andrade, "O grande cearense", que esse modo de pensar continuava inerente em nossos costumes pedagógicos extraescolares:

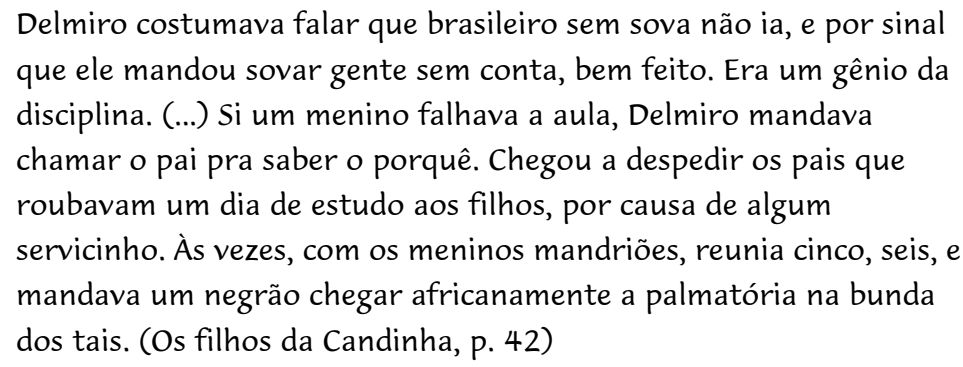

Voltemos outra vez no tempo.

Em 1839, o Presidente da Província de Minas Gerais, no desejo de melhor orientar a instrução, encarregou os técnicos Fernando Vaz de Melo e Francisco de Assis Peregrino do parecer sobre métodos e modificações a serem adotados. Peregrino, de volta da França, procurou descrever minuciosamente o chamado ensino simultâneo. Tratando da escola modelo, faz a lista dos instrumentos caídos em desuso. Entre estes se contavam os escritos de punição em quadros onde havia, com grandes caracteres, as palavras preguiçoso, falador, mentiroso, brincador. Esses quadros se afixavam (quando ainda vigia o costume) no peito dos alunos que fossem julgados merecedores desses epítetos desmoralizadores. Em suas considerações, o relator discorre sobre o dever dos professores: cooperar 
pela boa saúde dos condiscípulos, desenvolver sua inteligência e dirigir sua moralidade.

Também na Província de Minas Gerais, o professor Fulgêncio Moreira Maia Júnior, ao fazer um comentário sobre o ensino misto e descrever um dia de aula, deixa transparecer um detalhe a respeito da punição:

Às 9 horas, chamada. Revista da roupa, mãos, rosto e unhas. $\mathrm{O}$ aluno pouco asseado deveria ser lavado na própria aula, à vista de todos. (Mourão, 1959, p. 41)

Finalmente, mais um registro. No ano de 1867 , houve uma disposição oficial em Minas Gerais proscrevendo os castigos corporais usados durante muito tempo. A recomendação era a de só empregar a repreensão, o trabalho de leitura e de escrita fora das horas regulares, castigos que levassem o aluno ao vexame, a comunicação aos pais para castigos maiores $e$, por último, a expulsão da escola reservada aos alunos comprovadamente incorrigíveis -, medida extrema adotada depois de esgotados todos os outros meios coercitivos. Paulo K. Corrêa Mourão, em $O$ Ensino em Minas Gerais no tempo do Império, acrescenta:

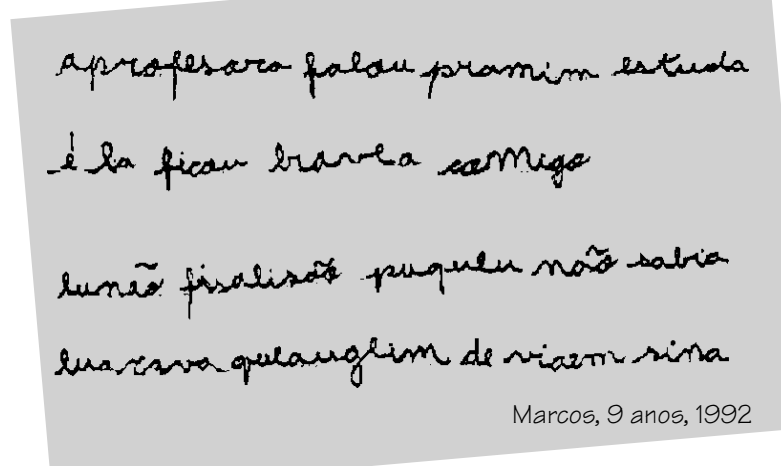

poderia haver também advertência

particular ou pública, mudança para lugar inferior na classe, tarefa extra etc. Permitia-se ainda - medida adotada até nos primeiros anos da República - por o aluno de pé ou de joelhos, até mesmo com os braços abertos. Esgotados os castigos propriamente escolares, o professor comunicaria ao pai do aluno o procedimento deste, quando não se emendasse. (1959, p. 41)

Talvez tenha sido o conhecimento desse ambiente rigidamente coercitivo que tenha levado Lúcia Miguel Pereira a sugerir estes possíveis acontecimentos:

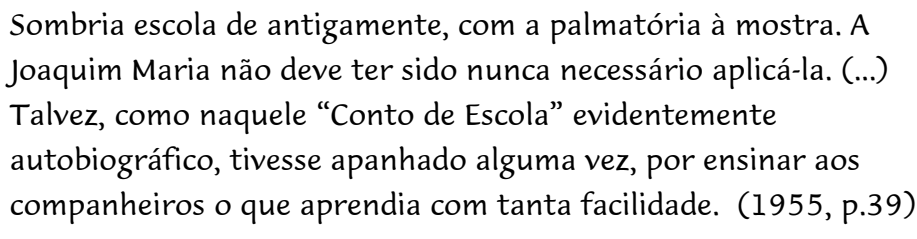

A figura do mestre-escola, referida constantemente em nossa literatura como objeto ironizado e também como instrumento da coerção e do medo, aparece várias vezes em Machado de Assis. Mas se trata de apenas um dos aspectos pelos quais o nosso maior escritor procura refletir sobre a 
educação. Não custa referir a importância que atribui ao seminário na formação de Bentinho em $D$. Casmurro ou os vínculos sugestivos que estabelece, pelo contraste entre natureza e cultura, entre o comportamento dos gêmeos Pedro e Paulo em Esaú e jacó e todo o processo de educação familiar.

Não há dúvida de que em Memórias Póstumas de Brás Cubas encontramos de modo sugestivo mais forte as contradições existentes na educação familiar. A volubilidade do personagem narrador e sua deformação de caráter encontram suas raízes nessa oposição entre a coerção pública, feita pelo pai, e o elogio na intimidade do lar, para o mesmo ato repreensível. Também neste grande romance, Machado de Assis aborda o tema da escola em dois capítulos. No XIII sintetiza suas observações sobre uma sala de aula de primeiras letras e, no XX, rememora a vida acadêmica de Brás Cubas.

Relembrando sua experiência como aluno de primeiras letras, Brás Cubas mistura mágoa e reconhecimento, como se os castigos e a disciplina rígida fossem uma necessidade da melhor formação. Citemos:

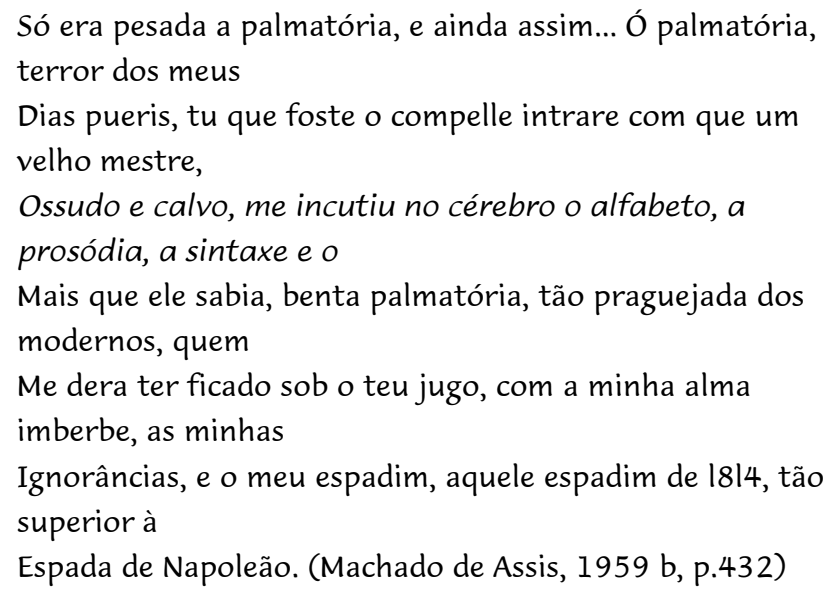

O romance também completa o ciclo da educação escolar tratando da universidade, de um modo que nos faz recordar o ambiente coimbrão descrito em $O$ reino da Estupidez, de Francisco de Mello Franco, e $O$ desertor das Letras de Manuel Inácio da Silva Alvarenga. $\mathrm{Na}$ linha dessa tradição crítica, Machado de Assis nos põe diante do contraste entre ensino e cultura ornamental, educação abstrata $e$ realidade concreta, titulação e (in)competência, contraste que uma leitura atenta descobrirá como característica freqüente em toda sua obra ao lado de outra, sutil ou explicitamente apresentada, que é a violência sob diferentes concretizações. Vejamos como isso se dá no conto escolhido.

$\mathrm{Na}$ maior parte de sua obra, Machado de Assis ocupou-se com a existência que se levava no Rio de Janeiro, principalmente enquanto lugar da Corte, mas também como capital da República nascente. Sonia Brayner observa, em $O$ conto de Machado de Assis, que em sua obra aos tipos, hábitos e cacoetes sócio-culturais do Rio de Janeiro, mescla- 
se a generalização de conceitos e observações sobre a natureza humana (1980, p. 11).

No Conto de Escola o assunto reduz-se a um episódio ocorrido em sala de aula, sendo que a própria progressão da narrativa incide mais sobre a psicologia das personagens que sobre a ação, pois o conto evolui no sentido de representar os tortuosos caminhos da formação moral. Mais preocupado com os procedimentos ou as atitudes do que com os fatos, o autor esboça as cenas com o realismo apropriado à visão e à experiência das coisas cotidianas. Por se definir por meio do desenvolvimento de um flagrante objetivo, explorando um acontecimento plausível pelo relato minudente, finalizando à maneira das fábulas e usando muito o diálogo, o conto parece ao mesmo tempo realista e clássico. E como o autor se vale do ponto de vista em primeira pessoa e nos remete a cenários de sua época, deixa-nos a impressão de autobiográfico. Trata-se de uma receita tipicamente machadiana que funde equilibradamente o antigo e o novo, o imaginário e o real pela apropriação criadora de um modelo que, em suas mãos, tornou-se algo original, conforme já assinalado por Agrippino Grieco:

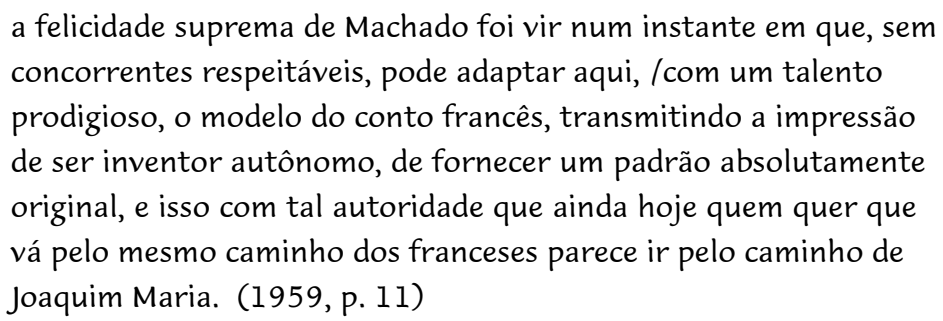

A delimitação espaço-temporal do conto, já a conhecemos: predomina a escola, o mês é maio, o ano 1840, no fim da Regência. Nessa época valia a excessiva rigidez na educação. O professor podia usar e abusar de sua autoridade, aplicando castigos corporais, de modo que a coerção social, própria de todo processo educativo, se fazia por meio da disciplina escolar apoiada em ameaças e violência física. $O$ personagem narrador, rememorando esses procedimentos, assim se exprime:

O pior que ele podia ter, para nós, era a palmatória. E essa lá estava, pendurada do portal da janela, à direita, com os seus cinco olhos do diabo. Era só levantar a mão, despendurá-la e brandi-la, com a força do costume, que não era pouca. (Machado de Assis, 1959a, p. 534)

E mais adiante descreve a prática punitiva:

Estendi-lhe a mão direita, depois a esquerda, e fui recebendo os bolos uns por cima dos outros, até completar doze, que me deixaram as palmas vermelhas $e$ inchadas. Chegou a vez do filho, $e$ foi a mesma cousa; não lhe poupou nada, dous, quatro, oito, doze bolos. Acabou, pregou-nos outro sermão. Chamou-nos semvergonhas, desaforados, e jurou que se repetíssemos o negócio, 
apanharíamos tal castigo que nos havia de lembrar para todo o sempre. E exclamava: Porcalhões! tratantes! faltos de brio!

(Machado de Assis, 1959a, p. 536)

Fica evidente que a violência física se soma à violência moral como modos de persuasão e como instrumentos de opressão e repressão que substituem qualquer outra pedagogia.

Referindo-se à possível intenção subjacente neste conto, Fernando Paixão escreve que

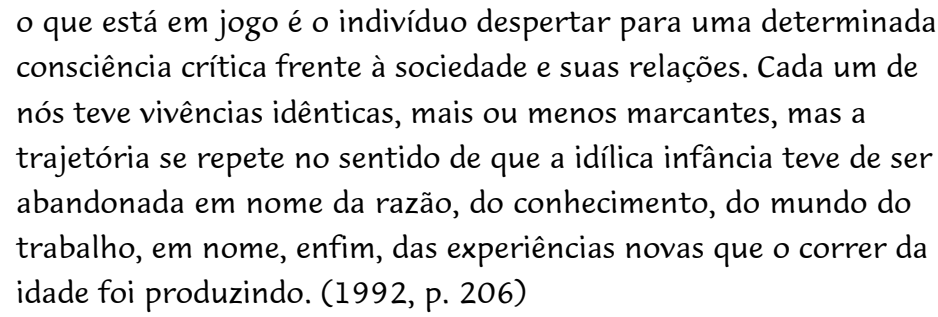

As personagens centrais do conto são o narrador (Pilar), Curvelo, Raimundo - meninos, os três - e Policarpo, o professor, pai de Raimundo. Dois mundos se opõem, o infantil e o adulto, sendo este a fonte do terror (que perpassa pela sala de aula) e de opressão violenta. Na esfera infantil, Pilar e Raimundo são os que se movem pela disciplina do castigo corporal, enquanto Curvelo, o delator, faz a ponte entre os dois mundos.

Como na realidade, a escola se apresenta como extensão da casa e da família. Tanto Pilar quanto Raimundo agem por medo aos pais, não sendo diferentes as punições sofridas dentro e fora do ambiente escolar. $O$ pai de Pilar, um ex-militar ríspido e intolerante (p.532), que vê na escola um meio de transformar o filho em caixeiro, não economiza a vara de marmelo. Quanto a Policarpo, que maltrata os alunos, demonstra maior severidade com o próprio filho, trazendo-o sob constante vigilância e em constante medo.

Nos breves diálogos travados entre Pilar e Raimundo, o tom de voz fica sempre baixo, como se os meninos se achatassem ao peso da autoridade do mestre. Nesse ambiente pesado, Raimundo e Pilar negociam com o conhecimento, Curvelo os denuncia, determinando o castigo descrito e a humilhação pública. Quase se pode concluir que a violência gera a corrupção $e$ a delação e estas desdobram aquela, numa cadeia sem fim.

Poder-se-ia concluir que Machado de Assis qualifica a escola de primeiras letras como lugar de origem da violência? Nada disso. Pode-se, sim, afirmar que nosso maior escritor deixa transparecer que as ações violentas deitam raízes na estrutura da sociedade. Quanto mais o poder constituído se fundar na autoridade privilegiada de uma classe, ou seja, quanto mais a manutenção do poder depender da manutenção de privilégios, mais o princípio de autoridade coercitiva se impõe, transformando as instituições sociais em

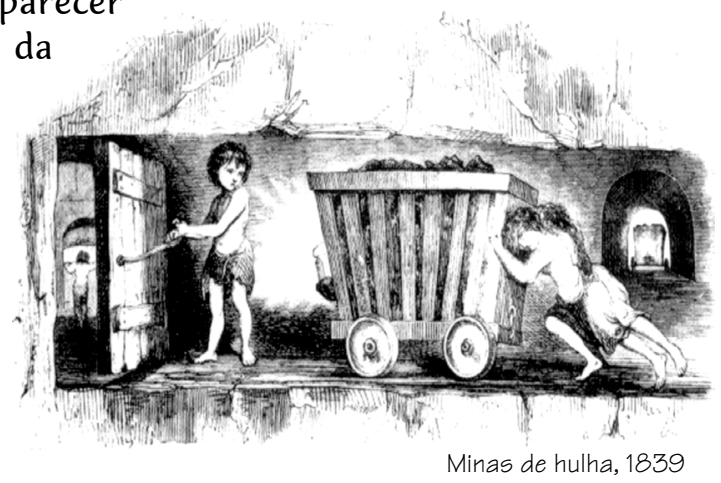


instrumentos dessa imposição. Machado de Assis, no conto, nada mais faz do que explicitar, esteticamente, essa instrumentação $e$ as conseqüências no processo de aprendizagem e na formação do caráter. Na sociedade do tempo, construída sobre a exploração dos vencedores sobre os vencidos, mantida pelo sistema de produção fundado no trabalho escravo, garantida na hegemonia política da classe senhorial, a violência, como ação contrária à ordem moral ou à ordem da natureza, constituía um imperativo categórico.

Restaria confirmar essa conclusão pela releitura de Memórias Póstumas de Brás Cubas (onde o escravo alforriado repete, quando patrão, a mesma violência sofrida tempos antes pelo senhor), pela leitura das crônicas escritas entre abril e junho de 1888, pela leitura de outros contos, inclusive o Conto Alexandrino, de Histórias sem Data (quando trata da "violência justificada" pela pesquisa científica) e, finalmente, pela análise de uma crônica sobre os motivos possíveis da crueldade humana, publicada em junho de $1895 \mathrm{com}$ o título de $O$ Autor de Si Mesmo. Tudo isso, porém, constitui assunto para outro trabalho.

\section{Referências bibliográficas}

ANDRADE, M. Os filhos da Candinha. São Paulo: Martins, 1963.

CALMON, P. História Social do Brasil. 2.ed. São Paulo: Nacional, 1937, v.1. (Coleção Brasiliana, 40).

FELIPPE, F. Aspectos do Romance Psicológico de Machado de Assis. Logos, Curitiba, n. 17, p. 54-9, 1953.

FREYRE, G. Casa-grande \& Senzala. 25.ed. Rio de Janeiro: José Olympio, 1987.

GRIECO, A. Machado de Assis. Rio de Janeiro: José Olympio, 1959.

MACHADO DE ASSIS, J. M. Conto de Escola. In: -.- Obra Completa. Rio de Janeiro: Aguilar, 1959. v.2, p. 532-537.

MACHADO DE ASSIS, J. M. Memórias Póstumas de Brás Cubas. In:-_- Obra

Completa. Rio de Janeiro: Aguilar, 1959, v. 1, p 409-549.

BRAYNER, S. O conto de Machado de Assis. In _-- (Org.). O conto de Machado de Assis: antologia. Rio de Janeiro: Civilização Brasileira; Brasília: INL, p. 7-17.

MATOS, M. Machado de Assis - o homem e a obra. São Paulo: Nacional, 1939.

MOACYR, P. A Instrução e o Império. São Paulo: Nacional, 1936.v.1. MOURÃO, P. K. C. O ensino em Minas Gerais no tempo do Império. Minas Gerais: Centro Regional de Pesquisas Educacionais, 1959.

PACHECO, J. A literatura brasileira - realismo. São Paulo: Cultrix, s.d., V.3.

PAIXÃO, F. A leitura como educação dos sentidos. COLE, 8. Anais. Campinas: Associação de Leitura do Brasil, 1992, p. 205-14.

PEIXOTO, A. Noções de história da educação. 2.ed. São Paulo: Nacional, 1936.

PEREIRA, L. M. Machado de Assis: estudo crítico e bibliográfico. 5.ed. Rio de Janeiro: José Olympio, 1955. 
GARCIA, S. C. G., SILVA, A. M. S. Violencia en las primeras letras: la escuela en un cuento de Machado de Assis, Interface _ Comunicação, Saúde, Educação, v.3 , n.5, 1999.

Basándose en el Cuento de Escuela de Machado de Assis, el texto reflexiona sobre la cuestión de la violencia en nuestra historia de la educación, analizando el proceso de formación escolar, vigente en Brasil hasta el siglo XIX, que consistía en que el profesor sujetase a sus alumnos por medio de instrumentos de coerción y miedo con el fin de formar su carácter, aunque para ello recurriese a actos violentos. A partir de los análisis desarrollados se puede pensar que cuanto más el poder se funde en el mantenimiento de privilegios de una classe, más la violencia se impone en la estructura social y, por tanto, en la educación, como una de sus instituciones.

PALABRAS-CLAVE: formación de carácter; educación; violencia.

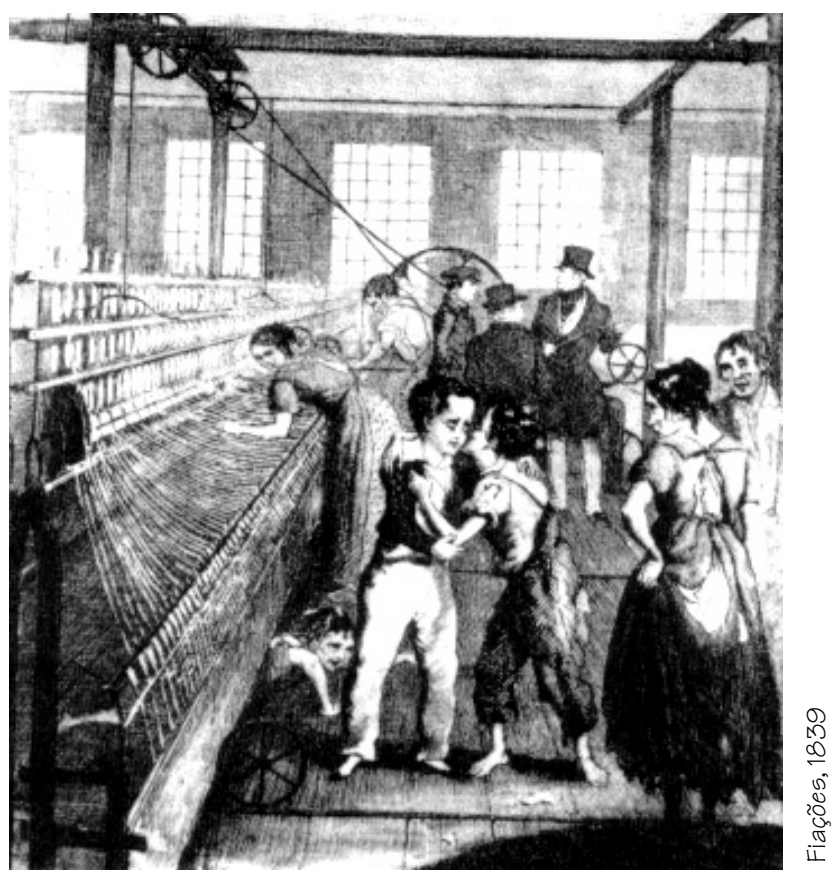

